\title{
OPEN Colonisation of the colonic mucus gel layer with butyrogenic and hydrogenotropic bacteria in health and ulcerative colitis
}

\author{
Helen Earley ${ }^{1,2,4}$, Grainne Lennon ${ }^{1,2,4}$, J. Calvin Coffey ${ }^{3,4}$, Desmond C. Winter ${ }^{2,4}$ \& \\ P. Ronan O'Connell1,2,4
}

Butyrate is the primary energy source for colonocytes and is essential for mucosal integrity and repair. Butyrate deficiency as a result of colonic dysbiosis is a putative factor in ulcerative colitis (UC). Commensal microbes are butyrogenic, while others may inhibit butyrate, through hydrogenotropic activity. The aim of this study was to quantify butyrogenic and hydrogenotropic species and determine their relationship with inflammation within the colonic mucus gel layer (MGL). Mucosal brushings were obtained from 20 healthy controls (HC), 20 patients with active colitis (AC) and 14 with quiescent colitis (QUC). Abundance of each species was determined by RT-PCR. Inflammatory scores were available for each patient. Statistical analyses were performed using Mann-Whitney-U and KruskallWallis tests. Butyrogenic $R$. hominis was more abundant in health than UC $(p<0.005)$, prior to normalisation against total bacteria. Hydrogenotropic $B$. wadsworthia was reduced in AC compared to HC and QUC $(p<0.005)$. An inverse correlation existed between inflammation and $R$. hominis $(\rho-0.460, p<0.005)$ and $B$. wadsworthia $(\rho-0.646, p<0.005)$. Other hydrogenotropic species did not widely colonise the MGL. These data support a role for butyrogenic bacteria in UC. Butyrate deficiency in UC may be related to reduced microbial production, rather than inhibition by microbial by-products.

The colonic microbiota plays a crucial role in the maintenance of homeostasis in the colon ${ }^{1}$. The short chain fatty acid (SCFA) butyrate is produced by microbial fermentation and is a key metabolite in the gastrointestinal tract $^{2,3}$. It is the primary energy source for colonocytes and also has anti-inflammatory actions, activates mucin release and protects the epithelial barrier ${ }^{4-8}$.

Reduced colonic butyrate concentration has been reported in UC and has been proposed as a potential aetiological factor in the pathogenesis of colonic inflammation ${ }^{9}$. In UC, changes also occur in the composition of the microbiota ${ }^{10,11}$, leading to the hypothesis that microbial factors may contribute to altered butyrate metabolism.

During mucin degradation, by-products are released ${ }^{12,13}$, which may be utilised as substrates for other bacterial species lacking mucolytic properties ${ }^{13,14}$. One such group of hydrogenotropic bacteria utilise these substrates to produce the toxic metabolite hydrogen sulphide $\left(\mathrm{H}_{2} \mathrm{~S}\right)^{15-17}$, that may induce inflammation through direct toxicity to the epithelium or inhibition of butyrate oxidation ${ }^{18-20}$. The most studied genus is Desulfovibrio ${ }^{21-23}$. However, little information exists on the involvement of other, less abundant species with hydrogenotropic potential in UC (Desulfobacter, Desulfobulbus and Bilophila wadsworthia) ${ }^{24,25}$. Other commensal species, such as $R$. hominis, are involved in the production of butyrate ${ }^{26}$. Butyrate levels in the colitic colon may be further reduced through reduced production by these species ${ }^{27-37}$.

The outer layer of the MGL provides an energy source and a growth medium for mucus-associated microbiota $^{38,39}$, which represents a community distinct from luminal bacteria ${ }^{40}$. This layer is therefore thought to represent the true host-microbial interface in the human colon ${ }^{40,41}$. The aims of this study were to determine the relative abundance of butyrogenic (R. hominis) and hydrogenotropic (Desulfobacter, Desulfobulbus and Bilophila wadsworthia) species and their relationship with inflammation within the mucus gel layer (MGL) of the colitic colon. This is the first study to quantitively analyse these species from brushings of the MGL.

\footnotetext{
${ }^{1}$ School of Medicine and Medical Science, University College Dublin, Belfield, Dublin 4, Ireland. ${ }^{2}$ Centre for Colorectal Disease, St Vincent's University Hospital, Dublin 4, Ireland. ${ }^{3}$ Graduate Entry Medical School, Limerick, Ireland. ${ }^{4}$ These authors contributed equally: Helen Earley, Grainne Lennon, J. Calvin Coffey, Desmond C. Winter and P. Ronan O'Connell. ${ }^{\circledR}$ email: helen.earley@ucdconnect.ie
} 


\begin{tabular}{|l|l|l|l|l|l|}
\hline Bacterial target & Forward Primer $\left(\mathbf{5}^{\prime}-\mathbf{3}^{\prime}\right)$ & Reverse Primer $\left(\mathbf{5}^{\prime}-\mathbf{3}^{\prime}\right)$ & Product Size $(\mathbf{b p})$ & Concentration $(\mathbf{n M})$ & References \\
\hline D. propionicus & $\begin{array}{l}\text { CGC GTA GAT AAC CTG } \\
\text { TCY TCA TG }\end{array}$ & $\begin{array}{l}\text { GTA GKA CGT GTG TAG } \\
\text { CCC TGG TC }\end{array}$ & 1120 & 250 & 63 \\
\hline D. curvatus & $\begin{array}{l}\text { GAT AAT CTG CCT TCA } \\
\text { AGC CTG G }\end{array}$ & $\begin{array}{l}\text { CYY YYY GCR RAG TCG } \\
\text { STG CCC T }\end{array}$ & 1150 & 250 & 63 \\
\hline B. wadsworthia & $\begin{array}{l}\text { CGT GTG AAT AAT GCG } \\
\text { AGG G }\end{array}$ & $\begin{array}{l}\text { TCT CCG GTA CTC AAG } \\
\text { CGT G }\end{array}$ & 207 & 200 & 64 \\
\hline R. hominis & $\begin{array}{l}\text { TAC TGC ATT GGA AAC } \\
\text { TGT CG }\end{array}$ & $\begin{array}{l}\text { CGG CAC CGA AGA } \\
\text { GCA AT }\end{array}$ & 230 & 100 & 65 \\
\hline
\end{tabular}

Table 1. 16S rRNA targeted PCR primer sequences used in this study and their expected amplicon sizes. ${ }^{\star}$ Denotes the use of a degenerate base pair. $Y=C / T, R=A / G, S=C / G, W=A / T, K=G / T$.

\section{Materials and methods}

Ethical approval, patient recruitment and sample collection. Ethical approval was obtained from the St. Vincent's University Hospital Ethics and Medical Research Committee. All methods were carried out in accordance with the relevant guidelines and regulations. All volunteers were over 18 years old and written informed consent was obtained. Three patient cohorts were established; healthy controls (HC), patients with quiescent UC (QUC) and patients with active UC (AC). All patient data were anonymised and coded to ensure patient confidentiality.

Healthy controls were recruited when undergoing routine diagnostic day case colonoscopy. No macroscopic evidence of mucosal pathology was evident in these individuals. Patients were excluded from the study if they had a history of antibiotic usage or hospital admission in the six weeks prior to colonoscopy, history of irritable bowel syndrome (IBS), indeterminate colitis, gastrointestinal malignancy or previous colorectal surgery.

Patients with quiescent UC were identified as having previously diagnosed, histologically confirmed UC and were undergoing surveillance colonoscopy. Exclusion criteria were as outlined above or evidence of UC associated dysplasia. Bowel preparations received by all patients undergoing colonoscopy were polyethylene glycol and sodium picosulphate based.

Patients in the AC cohort were recruited prior to undergoing surgical resection for disease refractory to medical management or those with acutely active UC failing to respond to rescue therapy (intravenous steroids, biologics or cyclosporine). Patients had not received bowel preparation prior to undergoing surgery, but had received a single dose of intravenous antibiotics prior to induction of anaesthesia, as per hospital protocol.

A biobank of clinical specimens was present in the form of extracted DNA in the School of Medicine and Medical Sciences in UCD. These DNA extracts were isolated from colonic mucus brushings and stored in sterile micro-centrifuge tubes at $-20^{\circ} \mathrm{C}$. Mucus brush samples were obtained using a Microbiological Protected Specimen Brush (Hobbs Medical Inc., Stafford Springs, Connecticut, USA). Samples were taken from the superficial layer of colonic mucus as previously described ${ }^{40}$. DNA was extracted using a Qiagen DNA Mini Kit (Qiagen, Hilden, Germany). The biobank of samples consisted of DNA from $20 \mathrm{HCs}, 14$ patients with QUC and 20 patients with AC. For each patient, samples were collected from four areas of the colon; caecum, transverse colon, left colon and rectum.

For each clinical sample the total copy number of bacteria per mg of mucus had previously been determined by quantitative RT-PCR ${ }^{42}$. Inflammatory scores had also been determined as previously described ${ }^{41}$. These data were available in a database for use as part of this study.

Construction of plasmid DNA standards. A series of plasmid DNA standards was generated to enable calculation of each bacterial copy number in each sample. In brief, freeze dried cultures of reference strains of Desulfobacter curvatus (ATCC 43,919) ${ }^{43}$, Desulfobulbus propionicus (ATCC 33,891) ${ }^{43}$, Bilophila wadsworthia

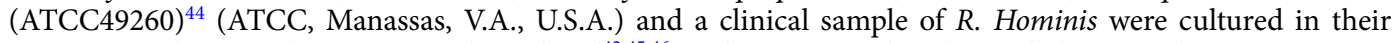
respective culture media as previously outlined ${ }^{42,45,46}$. Cultures were placed in a shaking incubator at $200 \mathrm{rpm}$ at $37^{\circ} \mathrm{C}$ for $72 \mathrm{~h}$ under anaerobic conditions achieved by the use of AnaeroGen anaerobic gas packs (Oxoid, Basingstoke, UK). DNA was extracted using a series of four heat freeze cycles at $-80^{\circ} \mathrm{C}$ and $100{ }^{\circ} \mathrm{C}$. Extracted DNA as outlined was used to generate positive controls for each bacterial target. Conventional PCR targeting the $16 \mathrm{~S}$ rRNA gene of bacterial targets was performed using previously published oligonucleotide primers sourced from Eurofins MWG GmbH (Eurofins MWG GmbH, Ebersberg, Germany) as outlined in Table 1. Assays for D. propionicus and D. curvatus were carried containing 1.25U GoTaqDNA polymerase (Promega Madison, WI, U.S.A.), $5 \times$ GoTaq Reaction Buffer (Promega), dNTPs at a final concentration of $0.2 \mathrm{mM}$, forward and reverse primers at final concentrations as outlined in Table 1 and $5 \mu$ of DNA template. Assays for B. wadsworthia, and R. hominis contained 2X My TaqRed Mix (Bioline, London, UK), primers at concentrations outlined in Table 1. The amplicons generated were cloned into a TOPO vector using the TOPO TA cloning system. DNA from the recombinant plasmid mini-preps were purified using the QIAprep Spin MiniPrep kit (Qiagen). The total weight per recombinant plasmid was calculated and this was used to generate a series of DNA standards of known copy number of the target sequence.

Detection and quantification of microbes in mucus brushings. For each clinical sample the total copy number of bacteria per mg of mucus had previously been determined by quantitative RT-PCR ${ }^{45}$. 

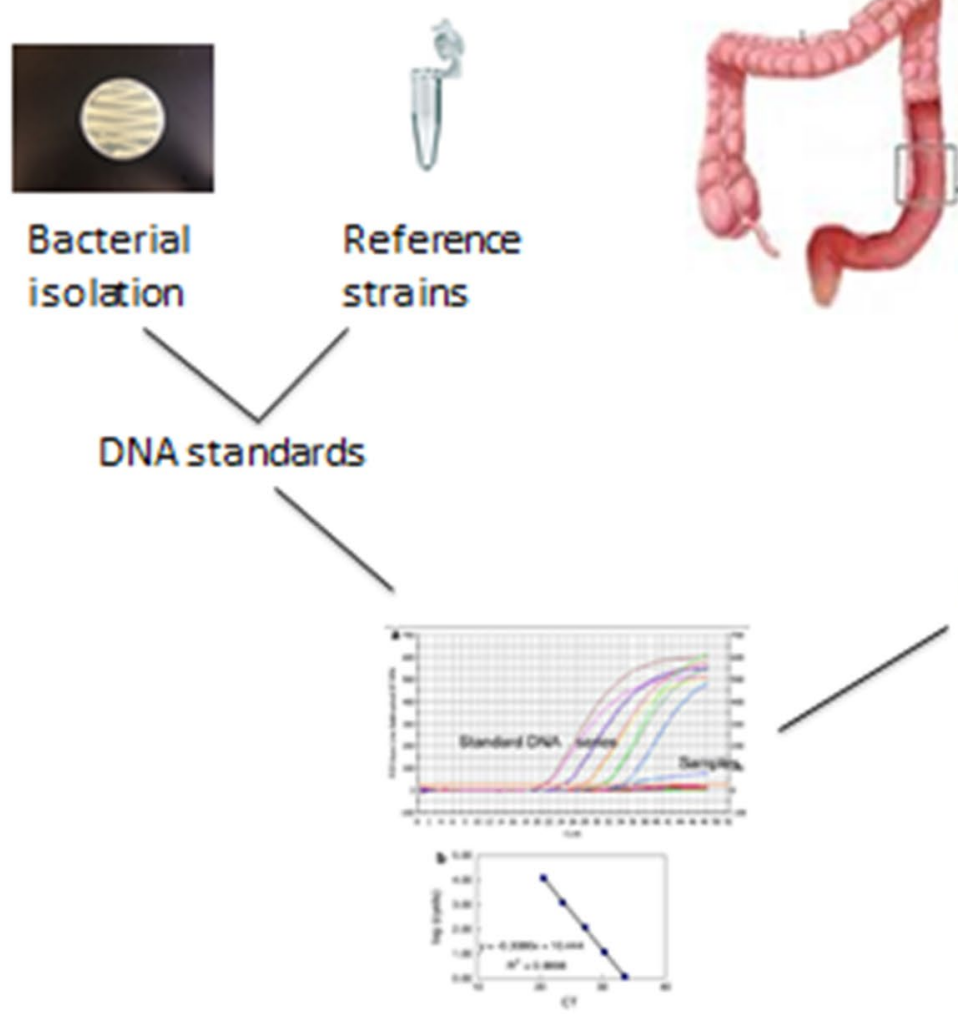

RT PCR

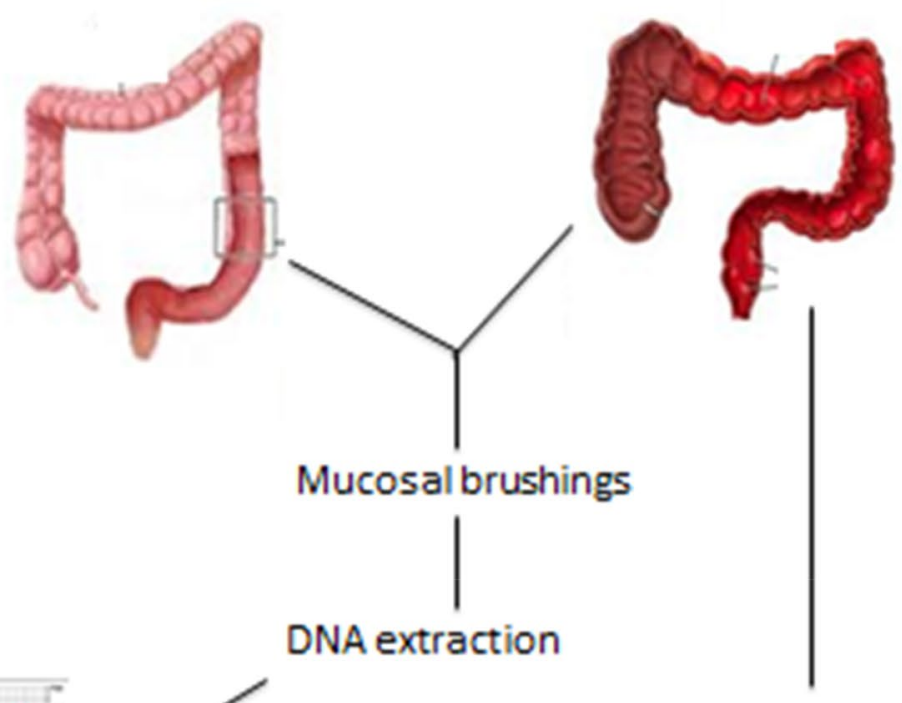

InflammatoryScores

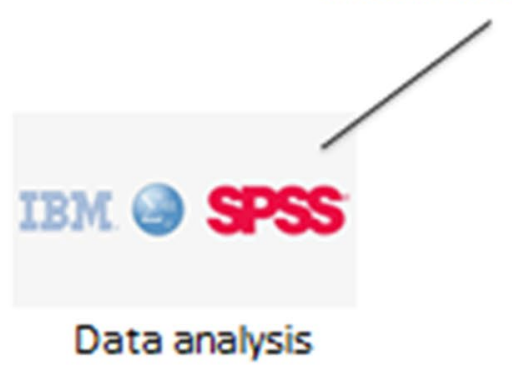

Figure 1. Schematic representing work flow through sample collection to data analysis.

RT PCR using an assay specific for the $16 \mathrm{~S}$ rRNA gene of each bacterial target was performed using primers outlined above. All PCR reactions for the targets D. propionicus, D. curvatus and B. wadsworthia were carried out on an Applied Biosystems7900HT Fast Real-Time PCR machine (Applied Biosystems Foster City, CA, USA.) using the primers outlined in Table 1 . Each reaction was performed in duplicate and carried out in an optical grade 384-well plate at a final volume of $20 \mu$ l. Each reaction consisted of 1X SyberGreen PCR Master Mix (Applied Biosystems), forward and reverse primers at concentrations outlined in Table 1 and $4 \mu \mathrm{l}$ of template DNA. For all bacterial targets standard cycling conditions and melt curve analysis were employed, plus additional annealing stages. For D. propionicus and D. curvatus incubations of $72{ }^{\circ} \mathrm{C}$ for $30 \mathrm{~s}$ and $79^{\circ} \mathrm{C}$ for $10 \mathrm{~s}$ were included. For B. wadsworthia an additional annealing stage at $79^{\circ} \mathrm{C}$ for $10 \mathrm{~s}$ was added. Reactions for R. hominis were carried out on an Illumina Eco Real Time PCR system machine (Illumina, San Diego, CA, USA) using standard annealing and melt curve analysis. Thermocycling conditions for $R$. hominis were; 40 cycles at $95^{\circ} \mathrm{C}$ for $30 \mathrm{~s}$, elongation at $55^{\circ} \mathrm{C}$ for $60 \mathrm{~s}$ and annealing at $72^{\circ} \mathrm{C}$ for $10 \mathrm{~s}$. Each reaction was carried out in an optical grade 48 -well plate at a final reaction volume of $10 \mu \mathrm{l}$, containing $1 X$ SensiFAST SYBR No-ROX Mix (Bioline) appropriate forward and reverse primers at final concentrations outlined in Table 1 and $4 \mu$ l of DNA template. All assays included water as a negative control and positive controls.

RT-PCR data analysis. Data analysis for all PCR assays performed on the Applied Biosystems platform was performed using SDS 2.4 software (Applied Biosystems). For assays performed on the Illumina platform (Illumina) EcoStudy software v 5.0 (Illumina) was used. Target copy number in each sample was determined based on the fold change $\left(2^{-\Delta \mathrm{Ct}}\right)$ relative to the $10^{7} \mathrm{copies} / \mu \mathrm{l}$ standard. Copy numbers were normalised for dilution volume, elution volume, DNA concentration and sample weight and for total bacterial copy numbers in each sample.

Statistical analysis. Normalised data were exported to SPSS statistics, version 20.0 (SPSS statistics, IBM, London, U.K.) for statistical analysis. Data were tested for normality of distribution, and statistical comparisons were performed based on Mann-Whitney U test and Kruskal-Wallis comparisons. Methods are summarised in Fig. 1. 


\begin{tabular}{|c|c|c|c|c|}
\hline & & $\mathrm{HC}$ & QUC & AC \\
\hline $\mathrm{n}$ & & 20 & 14 & 20 \\
\hline Age (years) & & $48.2(21-77)$ & $50.07(29-72)$ & $37.4(23-66)$ \\
\hline Gender (M/F) & & $16 / 4$ & $10 / 4$ & $12 / 8$ \\
\hline Time since diagnosis (years) & & $\mathrm{n} / \mathrm{a}$ & $18(10-33)$ & $5(2-14)$ \\
\hline Appendectomy & & 1 & 1 & 3 \\
\hline Smoking Status & \begin{tabular}{|l|} 
Current \\
Former \\
Never \\
\end{tabular} & $\begin{array}{l}0 \\
4 \\
9 \\
\end{array}$ & $\begin{array}{l}6 \\
2 \\
6 \\
\end{array}$ & \begin{tabular}{|l|}
2 \\
3 \\
9 \\
\end{tabular} \\
\hline \multirow{4}{*}{ Medication use } & Steroid & $\mathrm{n} / \mathrm{a}$ & 1 & 12 \\
\hline & 5-ASA & $\mathrm{n} / \mathrm{a}$ & 7 & 8 \\
\hline & Azathioprine & $\mathrm{n} / \mathrm{a}$ & 4 & 0 \\
\hline & Infliximab & $\mathrm{n} / \mathrm{a}$ & 0 & 12 \\
\hline Mean Mayo Score & & 0 & 0.25 & 10.3 \\
\hline
\end{tabular}

Table 2. Summary of characteristics of individuals in each cohort.

\begin{tabular}{|l|l|l|l|l|l|}
\hline Cohort & $\mathbf{n}$ & Median Copy No & IQR & Cohort Comparison & $\boldsymbol{p}$ value \\
\hline HC & 20 & $1.13 \mathrm{E}+5$ & $3.37 \mathrm{E}+5$ & HC-QUC & 0.072 \\
\hline QUC & 14 & $1.87 \mathrm{E}+5$ & $1.03 \mathrm{E}+6$ & HC-AC & 0.000 \\
\hline AC & 20 & $8.06 \mathrm{E}+2$ & $5.30 \mathrm{E}+3$ & QUC - AC & 0.000 \\
\hline Cohort & $\mathbf{n}$ & Median Normalised Copy No & IQR & Cohort Comparison & $\boldsymbol{p}$ value \\
\hline HC & 20 & $3.41 \mathrm{E}-3$ & $1.72 \mathrm{E}-2$ & HC-QUC & 0.388 \\
\hline QUC & 14 & $6.89 \mathrm{E}-3$ & $4.40 \mathrm{E}-2$ & HC-AC & 0.631 \\
\hline AC & 20 & $5.17 \mathrm{E}-3$ & $3.31 \mathrm{E}-2$ & QUC - AC & 0.627 \\
\hline
\end{tabular}

Table 3. Median copy number/mg and median relative abundance of $R$. hominis after normalisation for total bacterial copy number in each patient cohort. $p$ values for inter-cohort comparisons.

\section{Results}

Patient demographics. Fifty-four individuals were included in the study, comprising 20 patients with AC, 14 with QUC and $20 \mathrm{HC}$. Patients in the AC group were undergoing colectomy for disease refractory to medical management. No patients in this group had presented with an acute surgical emergency. Of the patients in the quiescent group, 5 underwent colonoscopy to monitor disease activity, the remaining 9 patients were undergoing screening colonoscopy procedures, eight of whom had disease duration of greater than ten years. As a result, the mean time since diagnosis was longer in the quiescent group than in the acute colitis group. In addition, the mean age in the QUC cohort (49 yrs) was also older than in the AC cohort (36 yrs). The mean age in the HC cohort was 48.2 yrs which closely resembled that of the quiescent cohort. The mean Mayo score of AC patients was 10.3, whereas the QUC cohort had a mean of 0.25 . Information with regard to smoking status, medication and previous appendectomy was available. A summary of patient demographics is outlined in Table 2.

Colonisation of the colon with butyrogenic species $\boldsymbol{R}$. hominis. $R$. hominis was detected in all individuals in the three cohorts. The abundance of $R$. hominis was significantly reduced in AC compared to HC and patients with QUC (Table 3, Fig. 2(i)). No significant difference was detected between the HC and those with QUC (Table 3). After normalisation for total bacterial copy number, no significant difference in relative abundance between any patient cohort was noted (Table 3 ). The reduction in abundance of $R$. hominis in the acute UC cohort compared to HC and QUC was observed in all four areas of the colon, caecum, transverse colon, left colon and rectum (Table 4). No significant difference in $R$. hominis abundance was detected between health and QUC across all four colonic regions.

Colonisation of the MGL with hydrogenotropic bacteria. Low rates of colonisation with the sulphate reducing D. curvatus and D. propionicus species were detected in all patient cohorts (Fig. 3). 40\% of patients were positive for D. propionicus in the HC and AC cohorts, and 10\% of patients in the QUC cohort. D curvatus was detected in $10 \%$ of patients with QUC. This species was not detected in healthy individuals or the AC cohort (Fig. 3). Given these findings, these microbes were eliminated from further study.

B. wadsworthia demonstrated a high colonisation rate in all three cohorts (HC 100\%, QUC 90\%, AC 95\%) (Fig. 3). Subsequent quantitative analysis was performed on this species. The abundance of $B$. wadsworthia was significantly reduced in patients with acute UC compared to health and patients with quiescent UC (Table 5, Fig. 4). No significant difference was detected between the healthy controls and those with quiescent UC (Table 5). 

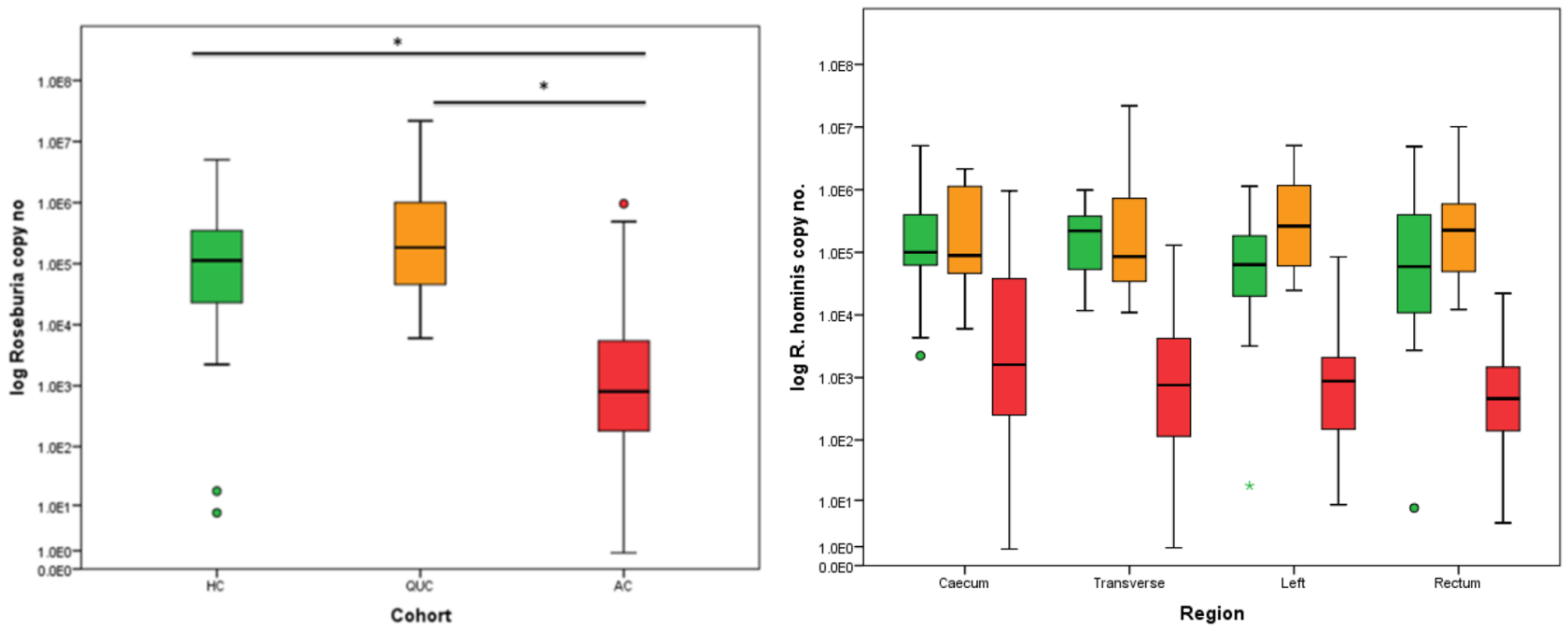

Figure 2. Boxplots representing inter-cohort comparisons of $R$. hominis. Healthy controls are represented in green, patents with quiescent UC in orange and patients with acute UC in red. ${ }^{\star}$ denotes $p<0.05$. Loco regional comparison along the longitudinal axis of the colon in the three patient cohorts.

\begin{tabular}{|c|c|c|c|c|c|c|c|c|c|c|c|c|}
\hline \multicolumn{13}{|c|}{ R. hominis copy no. } \\
\hline & \multirow[b]{2}{*}{$\mathbf{n}$} & \multicolumn{2}{|l|}{ HC } & \multirow[b]{2}{*}{$\mathbf{n}$} & \multicolumn{2}{|l|}{ QUC } & \multirow[b]{2}{*}{$\mathbf{n}$} & \multicolumn{2}{|l|}{ AC } & \multirow[b]{2}{*}{ HC-QUC } & \multirow[b]{2}{*}{ HC-ACact } & \multirow[b]{2}{*}{ QUC-AC } \\
\hline & & Median & IQR & & Median & IQR & & Median & IQR & & & \\
\hline Caecum & 16 & $1.00 \mathrm{E}+5$ & $3.75 \mathrm{E}+5$ & 11 & $8.93 \mathrm{E}+4$ & $1.27 \mathrm{E}+6$ & 17 & $1.61 \mathrm{E}+3$ & $4.56 \mathrm{E}+4$ & 0.716 & 0.000 & 0.001 \\
\hline Transverse & 17 & $2.20 \mathrm{E}+5$ & $3.51 \mathrm{E}+5$ & 13 & $8.56 \mathrm{E}+4$ & $2.47 \mathrm{E}+6$ & 16 & $7.62 \mathrm{E}+2$ & $4.85 \mathrm{E}+3$ & 0.869 & 0.000 & 0.000 \\
\hline Left & 15 & $6.57 \mathrm{E}+4$ & $1.85 \mathrm{E}+5$ & 11 & $2.62 \mathrm{E}+5$ & $2.19 \mathrm{E}+6$ & 16 & $8.87 \mathrm{E}+2$ & $2.29 \mathrm{E}+3$ & 0.039 & 0.000 & 0.000 \\
\hline Rectum & 15 & $5.93 \mathrm{E}+4$ & $5.08 \mathrm{E}+5$ & 11 & $2.25 \mathrm{E}+5$ & $9.55 \mathrm{E}+5$ & 16 & $4.64 \mathrm{E}+2$ & $1.46 \mathrm{E}+3$ & 0.305 & 0.000 & 0.000 \\
\hline \multicolumn{13}{|c|}{ Relative abundance of $\mathrm{R}$. hominis } \\
\hline & \multirow[b]{2}{*}{$\mathbf{n}$} & \multicolumn{2}{|c|}{ HC } & \multirow[b]{2}{*}{ n } & \multicolumn{2}{|l|}{ QUC } & \multirow[b]{2}{*}{$\mathbf{n}$} & \multicolumn{2}{|l|}{ AC } & \multirow[b]{2}{*}{ HC-QUC } & \multirow[b]{2}{*}{ HC-AC } & \multirow[b]{2}{*}{ QUC-AC } \\
\hline & & Median & IQR & & Median & IQR & & Median & IQR & & & \\
\hline Caecum & 15 & $1.99 \mathrm{E}-3$ & $1.33 \mathrm{E}-2$ & 9 & $1.04 \mathrm{E}-2$ & $8.62 \mathrm{E}-2$ & 13 & $4.79 \mathrm{E}-3$ & $1.37 \mathrm{E}-2$ & 0.387 & 0.982 & 0.301 \\
\hline Transverse & 16 & $2.93 \mathrm{E}-3$ & $2.38 \mathrm{E}-2$ & 10 & $8.62 \mathrm{E}-3$ & $1.27 \mathrm{E}-2$ & 14 & $3.37 \mathrm{E}-3$ & $2.10 \mathrm{E}-2$ & 0.916 & 0.934 & 0.815 \\
\hline Left & 15 & $2.76 \mathrm{E}-3$ & $2.76 \mathrm{E}-2$ & 9 & $1.70 \mathrm{E}-3$ & $6.84 \mathrm{E}-2$ & 15 & $3.70 \mathrm{E}-3$ & $5.32 \mathrm{E}-2$ & 0.698 & .0 .395 & 0.929 \\
\hline Rectum & 15 & $9.95 \mathrm{E}-3$ & $1.70 \mathrm{E}-2$ & 10 & $7.40 \mathrm{E}-3$ & $4.45 \mathrm{E}-2$ & 14 & $1.02 \mathrm{E}-2$ & $3.52 \mathrm{E}-2$ & 1.000 & 0.727 & 0.953 \\
\hline
\end{tabular}

Table 4. Comparison of $R$. hominis copy number and relative abundance on a loco-regional basis.

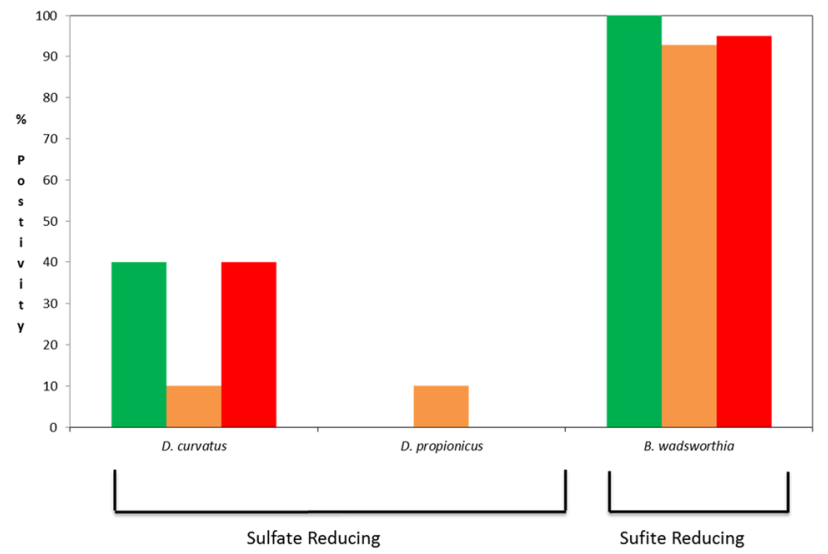

Figure 3. Colonisation rates of each bacterial target in each patient cohort. Healthy controls are represented in green, patients with quiescent UC in orange and patients with acute UC in red. 


\begin{tabular}{|l|l|l|l|l|l|}
\hline Cohort & $\mathbf{n}$ & Median copy No. & IQR & Cohort comparison & $\boldsymbol{p}$ value \\
\hline HC & 20 & $1.18 \mathrm{E}+04$ & $2.60 \mathrm{E}+04$ & HC-QUC & 0.546 \\
\hline QUC & 14 & $1.35 \mathrm{E}+04$ & $3.00 \mathrm{E}+04$ & HC-AC & 0.000 \\
\hline AC & 20 & $5.05 \mathrm{E}+00$ & $2.32 \mathrm{E}+02$ & QUC-AC & 0.000 \\
\hline Cohort & $\mathbf{n}$ & Median normalised copy No. & IQR & Cohort comparison & $\boldsymbol{p}$ value \\
\hline HC & 20 & $3.64 \mathrm{E}-04$ & $1.94 \mathrm{E}-02$ & HC-QUC & 0.467 \\
\hline QUC & 14 & $7.75 \mathrm{E}-04$ & $3.27 \mathrm{E}-03$ & HC-AC & 0.030 \\
\hline AC & 20 & $1.92 \mathrm{E}-04$ & $1.85 \mathrm{E}-03$ & QUC-AC & 0.150 \\
\hline
\end{tabular}

Table 5. Median copy number/mg and median relative abundance of B. wadsworthia after normalisation for total bacterial copy number in each patient cohort.
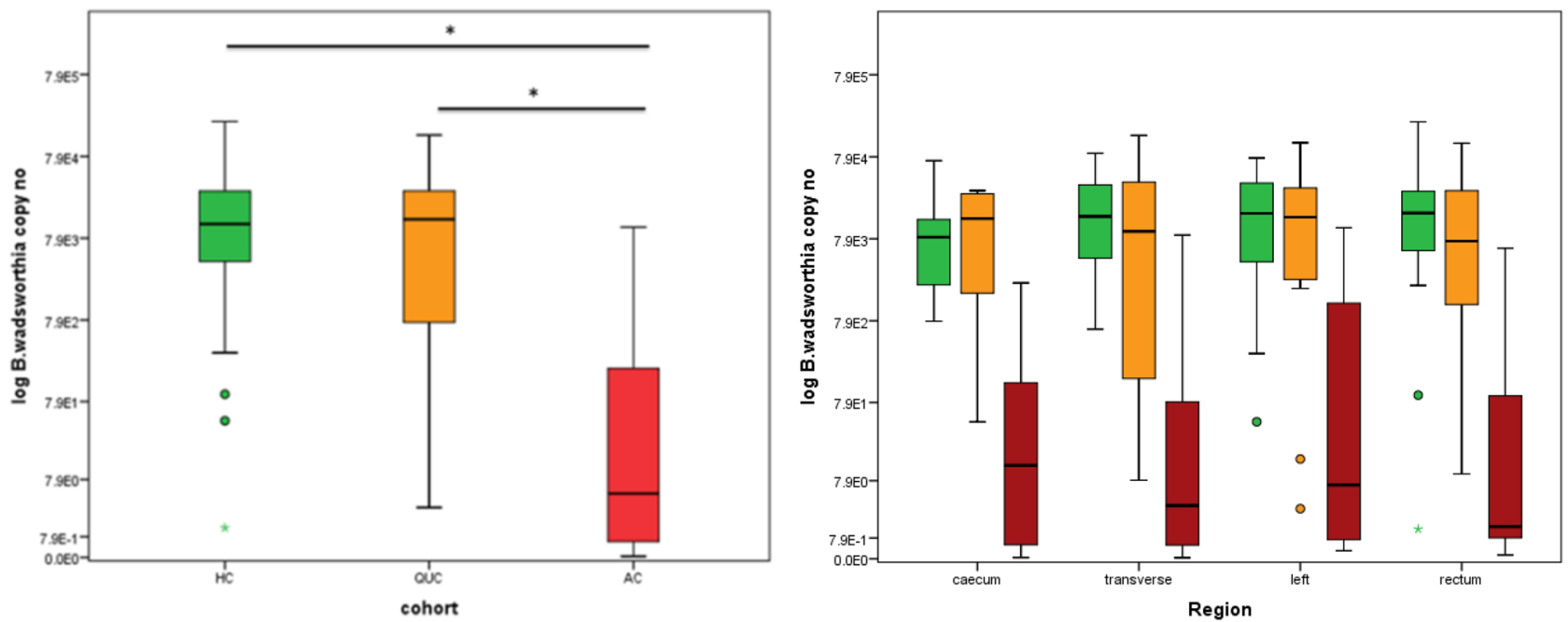

Figure 4. Boxplots representing inter-cohort comparisons of $B$. wadsworthia copy number Healthy controls are represented in green, patients with quiescent UC in orange and patients with acute UC in red. ${ }^{\star}$ denotes $p<0.05$. Comparison between areas of the colon.

\begin{tabular}{|c|c|c|c|c|c|c|c|c|c|c|c|c|}
\hline \multicolumn{13}{|c|}{ B. wadsworthia copy no } \\
\hline & \multirow[b]{2}{*}{$\mathbf{n}$} & \multicolumn{2}{|l|}{ HC } & \multirow[b]{2}{*}{$\mathbf{n}$} & \multicolumn{2}{|l|}{ QUC } & \multirow[b]{2}{*}{$\mathbf{n}$} & \multicolumn{2}{|l|}{ AC } & \multirow[b]{2}{*}{ HC-QUC } & \multirow[b]{2}{*}{ HC-AC } & \multirow[b]{2}{*}{ QUC-AC } \\
\hline & & Median & IQR & & Median & IQR & & Median & IQR & & & \\
\hline Caecum & 18 & $8.39 \mathrm{E}+03$ & $1.34 \mathrm{E}+04$ & 13 & $1.40 \mathrm{E}+04$ & $2.92 \mathrm{E}+04$ & 16 & $1.02 \mathrm{E}+01$ & $1.68 \mathrm{E}+02$ & 0.590 & 0.000 & 0.000 \\
\hline Transverse & 18 & $1.49 \mathrm{E}+04$ & $3.20 \mathrm{E}+04$ & 12 & $9.97 \mathrm{E}+03$ & $4.92 \mathrm{E}+04$ & 15 & $5.05 \mathrm{E}+00$ & $3.27 \mathrm{E}+02$ & 0.611 & 0.000 & 0.000 \\
\hline Left & 17 & $1.17 \mathrm{E}+04$ & $3.14 \mathrm{E}+04$ & 11 & $1.46 \mathrm{E}+04$ & $3.48 \mathrm{E}+04$ & 14 & $7.10 \mathrm{E}+00$ & $1.50 \mathrm{E}+03$ & 0.869 & 0.000 & 0.001 \\
\hline Rectum & 19 & $1.74 \mathrm{E}+04$ & $2.86 \mathrm{E}+04$ & 13 & $7.43 \mathrm{E}+03$ & $4.14 \mathrm{E}+04$ & 13 & $1.89 \mathrm{E}+00$ & $2.02 \mathrm{E}+02$ & 0.219 & 0.000 & 0.002 \\
\hline \multicolumn{13}{|c|}{ Normalised $B$. wadsworthia copy no. } \\
\hline & \multirow[b]{2}{*}{ n } & \multicolumn{2}{|c|}{ HC } & \multirow[b]{2}{*}{ n } & \multicolumn{2}{|l|}{ QUC } & \multirow[b]{2}{*}{$\mathbf{n}$} & \multicolumn{2}{|l|}{ AC } & \multirow[b]{2}{*}{ HC-QUC } & \multirow[b]{2}{*}{ HC-AC } & \multirow[b]{2}{*}{ QUC-AC } \\
\hline & & Median & IQR & & Median & IQR & & Median & IQR & & & \\
\hline Caecum & 18 & $2.32 \mathrm{E}-04$ & $8.63 \mathrm{E}-03$ & 13 & $4.44 \mathrm{E}-04$ & $2.01 \mathrm{E}-02$ & 16 & $5.36 \mathrm{E}-05$ & $1.39 \mathrm{E}-03$ & 0.701 & 0.241 & 0.635 \\
\hline Transverse & 18 & $4.38 \mathrm{E}-04$ & $1.66 \mathrm{E}-02$ & 12 & $9.46 \mathrm{E}-04$ & $3.02 \mathrm{E}-03$ & 15 & $6.47 \mathrm{E} 0-6$ & $2.51 \mathrm{E}-03$ & 0.421 & 0.072 & 0.157 \\
\hline Left & 17 & $2.65 \mathrm{E}-04$ & $9.10 \mathrm{E}-03$ & 11 & $1.34 \mathrm{E}-03$ & $3.44 \mathrm{E}-03$ & 14 & $8.39 \mathrm{E}-04$ & $1.14 \mathrm{E}-02$ & 0.729 & 0.771 & 0.953 \\
\hline Rectum & 19 & $5.81 \mathrm{E}-04$ & $6.13 \mathrm{E}-02$ & 13 & $4.29 \mathrm{E}-04$ & $3.88 \mathrm{E}-03$ & 13 & $2.55 \mathrm{E}-04$ & $7.87 \mathrm{E}-04$ & 0.388 & 0.189 & 0.369 \\
\hline
\end{tabular}

Table 6. Comparison of B. wadsworthia copy number and relative abundance on a loco-regional basis.

After normalisation for total bacterial copy number, a persistent significant reduction in the relative abundance of $B$. wadsworthia was noted in the acute UC cohort compared to the healthy cohort (Table 5). No significant difference in normalised $B$. wadsworthia copy number was noted between healthy patients and patients with quiescent UC, or between the quiescent UC group and those with acute colitis (Table 5). The reduction in abundance of $B$. wadsworthia in the acute UC cohort compared to health and quiescent UC was observed in all four areas of the colon, caecum, transverse colon, left colon and rectum. No significant difference in $B$. wadsworthia 
abundance was detected between health and quiescent UC across all four colonic regions (Table 6, Fig. 4.). After normalisation against total-bacterial copy number, no significant difference was noted between patients with acute UC or quiescent UC compared to health in any of the four colonic regions examined (Table 6).

Correlation of butyrogenic and hydrogenotropic bacteria with inflammatory cell infiltrates. To determine whether the abundance of R. hominis or B. wadsworthia in the colon was associated with markers of inflammation, correlations with inflammatory cell infiltrates were performed. A negative correlation existed between inflammatory cell infiltrate and abundance of $B$. wadsworthia, $(\rho-0.646, p=0.000)$. A negative association was also found between inflammatory cell infiltrate and abundance of $R$. hominis, $(\rho-0.460$, $p=0.000)$.

\section{Discussion}

The present study uses protected specimen brushings of the colonic mucosa as the sampling method ${ }^{40}$. This unique approach to studying the innate microbiota has several advantages. It minimises contamination with luminal contents compared to faecal sampling and obtains a higher proportion of bacterial DNA than host DNA when compared to mucosal biopsies ${ }^{40,47}$. Faecal samples, the MGL and mucosa have each been shown to harbour distinct microbial communities ${ }^{48}$. Mucus brushings are believed to yield findings that are more representative of the true burden of these species within the outer layer of the MGL, which represents the true host-microbial interface in the human colon $^{39,40,47}$.

The primary aim of this study was to perform quantitative analysis of $R$. hominis, a species known to produce substantial amounts of butyrate in vitro ${ }^{49}$. This species widely colonised the MGL in health and UC, indicating that this is an ubiquitous member of the innate microflora. Its' abundance was reduced in patients with AC compared to health and QUC. This reduction was observed in all four colonic regions, supporting the hypothesis that UC is associated with a global dysbiosis and the concept of spatial homogeneity along the longitudinal axis of the colon ${ }^{42,48}$. An inverse correlation between $R$. hominis abundance and inflammatory cell infiltrates was demonstrated, indicating that depletion of this species is a feature of inflammation in the colitic colon.

In keeping with these data, reductions in the abundance of this species, as well as an inverse correlation with disease severity, have been reported in UC in previous studies based on faecal sampling ${ }^{28,32}$. However, studies of mucosal biopsies yielded conflicting results ${ }^{50,51}$. Willing et al.reported a reduction in $R$. hominis in patients with ileal CD, but not $\mathrm{UC}^{50}$, while Lepage et al.reported no reduction in the species in mucosal biopsies of twins with $U^{51}$. These findings, combined with the observation by Machiels et al.that a stable reduction occurred in the faeces of patients with quiescent disease, led to the hypothesis that alterations in Roseburia abundance may play a role in the study of the transient microbiota, rather than the adherent microbiota ${ }^{28}$. The current study challenges this theory, suggesting that the reduction in $R$. hominis contributes to the dysbiosis of the MGL adherent microbiota in the inflamed colon, with abundances returning towards healthy levels when disease is in remission. $R$. hominis has been shown to have anti-inflammatory mechanisms in vitro ${ }^{52}$. It is tempting to hypothesise that this is related to the production of butyrate however, the authors acknowledge that this cannot be inferred from compositional data alone.

This study also aimed to determine colonisation patterns of $\mathrm{H}_{2} \mathrm{~S}$ producing species. Desulfovibrio remains the most studied of these bacteria and to date a consensus has not been reached as to their precise role in $\mathrm{UC}^{25,45,53,54}$. Few studies analysed other low-abundance microbes such as D. desulfuricans and D. propionicus, both of which are capable of foraging sulfate and producing $\mathrm{H}_{2} \mathrm{~S}^{24}$. No data currently exist pertaining to the involvement of these species in UC. This study demonstrated low colonisation rates of D. desulfuricans and D. propionicus in both health and UC. $40 \%$ of healthy subjects were positive for D. curvatus in the current study, in keeping with data from Gibson et al., who reported hydrogenotropic species in $50 \%$ of faecal samples ${ }^{55}$. On the other hand, it is at odds Nava et al.who detected both species in mucosal biopsies of 25 healthy subjects ${ }^{56}$. It should also be noted that in the aforementioned study, the species Desulfovibrio accounted for the majority of hydrogenotropic present. Previous work from our laboratory demonstrated a high rate of colonisation with Desulfovibrio ${ }^{45}$ in these patient samples. Desulfovibrio may be the dominant species of sulphate reducing bacteria colonising this patient cohort also. Given the low colonisation rates of $D$. desulfuricans and D. proprionicus in UC, there is no compelling evidence of an association between these species and UC in the present study.

B. wadsworthia was present at detectable levels in the majority of individuals in this study. These data demonstrate a significant reduction in $B$. wadsworthia in patients with AC compared to healthy individuals and those with QUC. The reduced abundance in patients with AC compared to healthy individuals remained significant after normalisation against total bacterial counts. The inverse correlation between $B$. wadsworthia abundance and inflammatory score confirm that a reduction in abundance of this species is a feature of the inflamed colon. Although these findings are not in keeping with the hypothesis of increased activity of hydrogenotropic bacteria in UC, the finding is nonetheless significant. These data suggest a tentative link between this species and dysbiosis in AC.

These results are consistent with previously published findings using faecal samples, reporting a reduction in B.wadsworthia in patients with Crohn's disease before treatment compared to health ${ }^{25}$. However it should be noted that these findings differ from those in murine models, where B. wadsworthia has been reported to act as a pathobiont, promoting the development of inflammation ${ }^{57,58}$. Evidence suggests that In vivo results of murine models cannot always be extrapolated easily to humans $\mathrm{s}^{59,60}$, which should be considered when interpreting the contrasting results pertaining to this species reported in human and murine models.

In this study, normalisation of data against total bacterial copy number was performed to reduce potential reporting errors by minimising the effect of between-sample variation and taking the efficiency of the quantification procedure into account for both species investigated. These data are more representative of the actual burden 
of the target in the MGL. However, normalisation negated the significant difference in abundance observed between health and acute UC when analysis was based on raw copy numbers at each of the four colonic regions examined. This may be due to the fact that individually, these species account for a small proportion of the overall bacterial load at any given site in the colon.

It is likely that several factors contribute to the observed reduction in abundance in these species in UC. Changes in the ecosystem of the MGL as a result of the inflammatory process may result in suboptimal conditions for bacterial survival. To date, no study has specifically addressed the potential interactions between hydrogenotropic, butyrogenic and other species within the MGL in the colitic colon. The authors have previously demonstrated a reduction in mucolytic bacteria in $\mathrm{UC}^{41}$, which due to reduced mucin degradation, may lead to a lack of substrate for these bacteria. Hydrogenotropic bacteria have also been shown to impact host physiology ${ }^{61}$. It is possible that $B$. wadsworthia has properties that enable SCFA production. A recently published study demonstrated an association between $B$. wadsworthia and higher butyric acid concentrations in faecal samples of healthy infants ${ }^{62}$, suggesting a potential link between the species and SCFA production in the human colon.

This study investigated the microbiological basis of UC as an energy deficiency disease, with specific focus on butyrogenic and hydrogenotropic bacteria at the level of the MGL. In keeping with the hypothesis that UC is associated with reduced butyrate concentrations, reductions in the abundance of $R$. hominis were noted. However reduced abundance of the hydrogenotropic $B$. wadsworthia was also observed in the colitic colon in this study. These data suggest that the reported lack of butyrate in the colitic colon may be a result of a lack of butyrogenic bacteria, rather than bacterial inhibition by microbial by-products such as $\mathrm{H}_{2} \mathrm{~S}$. Furthermore, altered abundances of these species are associated with active inflammation in UC. Overall, these data suggest that reductions in these species are a feature of the altered microbial signature of the MGL in UC.

\section{Limitations}

The authors acknowledge that the current study has some limitations. It is possible that the use of bowel preparation may have resulted in a loss of some loosely adherent microbes in the patients undergoing colonoscopy (HC ad), however, this would not account for the low colonisation rates in patients with acute UC, as this cohort did not receive bowel preparation prior to surgery. This would be difficult to control for, as adequate bowel preparation is a prerequisite for successful colonoscopy. This study did not determine whether the observed alterations in microbes equated to alterations in butyrate levels in the colon. Further functional studies are warranted to validate these findings. Finally, as with many studies of the microbiota, the authors acknowledge that it is not possible to determine from these data whether the observed changes are a potential driving force behind the pathogenesis of inflammation, or arising as a result of the inflammatory process. The association between these microbial changes and UC warrants further investigation, with a view to establishing whether a cause-effect relationship indeed exists, and whether manipulation of the dysbiosis in UC will have clinical applications in the future.

Received: 24 November 2020; Accepted: 18 February 2021

Published online: 31 March 2021

\section{References}

1. Montalto, M., D’Onofrio, F., Gallo, A., Cazzato, A. \& Gasbarrini, G. Intestinal microbiota and its functions. Digest. Liver Dis. Suppl. 3(2), 30-34 (2009).

2. Clausen, M. R. \& Mortensen, P. B. Kinetic studies on the metabolism of short-chain fatty acids and glucose by isolated rat colonocytes. Gastroenterology 106(2), 423-432 (1994).

3. Louis, P. \& Flint, H. J. Formation of propionate and butyrate by the human colonic microbiota. Environ. Microbiol. 19(1), 29-41 (2017).

4. Hamer, H. M. et al. Review article: the role of butyrate on colonic function. Aliment. Pharmacol. Ther. 27(2), 104-119 (2008).

5. Bach Knudsen, K. E. \& Lærke, H. N. Impact of diet-modulated butyrate production on intestinal barrier function and inflammation. Nutrients 10(10), 1499 (2018).

6. Ploger, S. et al. Microbial butyrate and its role for barrier function in the gastrointestinal tract. Ann. N. Y. Acad. Sci. 1258, 52-59 (2012).

7. Klampfer, L., Huang, J., Sasazuki, T., Shirasawa, S. \& Augenlicht, L. Inhibition of interferon gamma signaling by the short chain fatty acid butyrate. Mol. Cancer Res. MCR 1(11), 855-862 (2003).

8. Chang, P. V., Hao, L. M., Offermanns, S. \& Medzhitov, R. The microbial metabolite butyrate regulates intestinal macrophage function via histone deacetylase inhibition. Proc. Natl. Acad. Sci. U.S.A. 111(6), 2247-2252 (2014).

9. Roediger, W. E. The colonic epithelium in ulcerative colitis: an energy-deficiency disease?. Lancet 2(8197), 712-715 (1980).

10. Nishida, A. et al. Gut microbiota in the pathogenesis of inflammatory bowel disease. Clin. J. Gastroenterol. 11(1), 1-10 (2018).

11. Khan, I. et al. Alteration of gut microbiota in inflammatory bowel disease (IBD): cause or consequence IBD treatment targeting the gut microbiome. Pathogens 8(3), 126 (2019).

12. Willis, C. L., Cummings, J. H., Neale, G. \& Gibson, G. R. In vitro effects of mucin fermentation on the growth of human colonic sulphate-reducing bacteria ecology. Anaerobe 2(2), 117-122 (1996).

13. Png, C. W. et al. Mucolytic bacteria with increased prevalence in IBD mucosa augment in vitro utilization of mucin by other bacteria. Am. J. Gastroenterol. 105(11), 2420-2428 (2010).

14. Laue, H., Denger, K. \& Cook, A. M. Taurine reduction in anaerobic respiration of Bilophila wadsworthia RZATAU. Appl. Environ. Microbiol. 63(5), 2016-2021 (1997).

15. Carbonero, F., Benefiel, A. C., Alizadeh-Ghamsari, A. H. \& Gaskins, H. R. Microbial pathways in colonic sulfur metabolism and links with health and disease. Front. Physiol. 3, 448 (2012).

16. Pfennig, N. \& Widdel, F. The bacteria of the sulphur cycle. Philos. Trans. R. Soc. Lond. B Biol. Sci. 298(1093), $433-441$ (1982).

17. Devereux, R., Delaney, M., Widdel, F. \& Stahl, D. A. Natural relationships among sulfate-reducing eubacteria. J. Bacteriol. 171(12), 6689-6695 (1989).

18. Pitcher, M. C. \& Cummings, J. H. Hydrogen sulphide: a bacterial toxin in ulcerative colitis?. Gut 39(1), 1-4 (1996).

19. Roediger, W. E., Duncan, A., Kapaniris, O. \& Millard, S. Reducing sulfur compounds of the colon impair colonocyte nutrition: implications for ulcerative colitis. Gastroenterology 104(3), 802-809 (1993). 
20. Roediger, W. E., Moore, J. \& Babidge, W. Colonic sulfide in pathogenesis and treatment of ulcerative colitis. Dig. Dis. Sci. 42(8), 1571-1579 (1997).

21. Loubinoux, J., Bronowicki, J. P., Pereira, I. A., Mougenel, J. L. \& Faou, A. E. Sulfate-reducing bacteria in human feces and their association with inflammatory bowel diseases. FEMS Microbiol. Ecol. 40(2), 107-112 (2002).

22. Mills, D. J. et al. Dietary glycated protein modulates the colonic microbiota towards a more detrimental composition in ulcerative colitis patients and non-ulcerative colitis subjects. J. Appl. Microbiol. 105(3), 706-714 (2008).

23. Khalil, N. A., Walton, G. E., Gibson, G. R., Tuohy, K. M. \& Andrews, S. C. In vitro batch cultures of gut microbiota from healthy and ulcerative colitis (UC) subjects suggest that sulphate-reducing bacteria levels are raised in UC and by a protein-rich diet. Int. J. Food Sci. Nutr. 65(1), 79-88 (2014).

24. Gibson, G. R., Macfarlane, G. T. \& Cummings, J. H. Occurrence of sulphate-reducing bacteria in human faeces and the relationship of dissimilatory sulphate reduction to methanogenesis in the large gut. J. Appl. Bacteriol. 65(2), 103-111 (1988).

25. Jia, W. et al. Diversity and distribution of sulphate-reducing bacteria in human faeces from healthy subjects and patients with inflammatory bowel disease. FEMS Immunol. Med. Microbiol. 65(1), 55-68 (2012).

26. Tilg, H. \& Danese, S. Roseburia hominis: a novel guilty player in ulcerative colitis pathogenesis?. Gut 63, 1204-1205 (2013).

27. Joossens, M. et al. Dysbiosis of the faecal microbiota in patients with Crohn's disease and their unaffected relatives. Gut 60(5), 631-637 (2011).

28. Machiels, K. et al. A decrease of the butyrate-producing species Roseburia hominis and Faecalibacterium prausnitzii defines dysbiosis in patients with ulcerative colitis. Gut 63, 1275-1283 (2013).

29. Sokol, H. et al. Faecalibacterium prausnitzii is an anti-inflammatory commensal bacterium identified by gut microbiota analysis of Crohn disease patients. Proc. Natl. Acad. Sci. U.S.A. 105(43), 16731-16736 (2008).

30. Varela, E. et al. Colonisation by Faecalibacterium prausnitzii and maintenance of clinical remission in patients with ulcerative colitis. Aliment. Pharmacol. Ther. 38(2), 151-161 (2013).

31. Kumari, R., Ahuja, V. \& Paul, J. Fluctuations in butyrate-producing bacteria in ulcerative colitis patients of North India. World J. Gastroenterol. WJG 19(22), 3404-3414 (2013).

32. Rajilic-Stojanovic, M., Shanahan, F., Guarner, F. \& de Vos, W. M. Phylogenetic analysis of dysbiosis in ulcerative colitis during remission. Inflamm. Bowel Dis. 19(3), 481-488 (2013).

33. Eeckhaut, V. et al. Butyricicoccus pullicaecorum in inflammatory bowel disease. Gut 62(12), 1745-1752 (2013).

34. Martinez-Medina, M., Aldeguer, X., Gonzalez-Huix, F., Acero, D. \& Garcia-Gil, L. J. Abnormal microbiota composition in the ileocolonic mucosa of Crohn's disease patients as revealed by polymerase chain reaction-denaturing gradient gel electrophoresis. Inflamm. Bowel Dis. 12(12), 1136-1145 (2006).

35. Angelberger, S. et al. Temporal bacterial community dynamics vary among ulcerative colitis patients after fecal microbiota transplantation. Am. J. Gastroenterol. 108(10), 1620-1630 (2013).

36. Li, E. et al. Inflammatory bowel diseases phenotype, C. difficile and NOD2 genotype are associated with shifts in human ileum associated microbial composition. PLoS ONE 7(6), e26284 (2012).

37. Jia, W. et al. Is the abundance of Faecalibacterium prausnitzii relevant to Crohn's disease?. FEMS Microbiol. Lett. 310(2), 138-144 (2010).

38. Macfarlane, S. \& Dillon, J. F. Microbial biofilms in the human gastrointestinal tract. J. Appl. Microbiol. 102(5), 1187-1196 (2007).

39. Johansson, M. E., Larsson, J. M. \& Hansson, G. C. The two mucus layers of colon are organized by the MUC2 mucin, whereas the outer layer is a legislator of host-microbial interactions. Proc. Natl. Acad. Sci. U.S.A. 108(Suppl 1), 4659-4665 (2011).

40. Lavelle, A. et al. Depth-dependent differences in community structure of the human colonic microbiota in health. PLoS ONE 8(11), e78835 (2013).

41. Earley, H. et al. The abundance of Akkermansia muciniphila and its relationship with sulphated colonic mucins in health and ulcerative colitis. Sci. Rep. 9(1), 15683 (2019).

42. Lavelle, A. Spatial Structure of the Microbiota in Health and Ulcerative Colitis. PhD thesis. University College Dublin: University College Dublin (2014).

43. Fite, A. et al. Identification and quantitation of mucosal and faecal desulfovibrios using real time polymerase chain reaction. Gut 53(4), 523-529 (2004).

44. Baron, E. J. Bilophila wadsworthia: a unique Gram-negative anaerobic rod. Anaerobe 3(2-3), 83-86 (1997).

45. Lennon, G. et al. Correlations between colonic crypt mucin chemotype, inflammatory grade and Desulfovibrio species in ulcerative colitis. Colorect. Dis. 16(5), O161-169 (2014).

46. Earley, H. Mucolytic, hydrogen sulphide producing and butryate producing bacteria in Ulcerative colitis-unravelling the dysbiosis concept (University College Dublin, 2016).

47. Huse, S. M. et al. Comparison of brush and biopsy sampling methods of the ileal pouch for assessment of mucosa-associated microbiota of human subjects. Microbiome 2(1), 5 (2014).

48. Lavelle, A. et al. Spatial variation of the colonic microbiota in patients with ulcerative colitis and control volunteers. Gut 64, 1553-1561 (2015).

49. Duncan, S. H., Hold, G. L., Barcenilla, A., Stewart, C. S. \& Flint, H. J. Roseburia intestinalis sp. Nov., a novel saccharolytic, butyrateproducing bacterium from human faeces. Int. J. Syst. Evol. Microbiol. 52(5), 1615-1620 (2002).

50. Willing, B. P. et al. A pyrosequencing study in twins shows that gastrointestinal microbial profiles vary with inflammatory bowel disease phenotypes. Gastroenterology 139(6), 1844-1854.e1841 (2010).

51. Lepage, P. et al. Twin study indicates loss of interaction between microbiota and mucosa of patients with ulcerative colitis. Gastroenterology 141(1), 227-236 (2011).

52. Patterson, A. M. et al. Human gut symbiont roseburia hominis promotes and regulates innate immunity. Front. Immunol. 8, 1166 (2017).

53. Rowan, F. E., Docherty, N. G., Coffey, J. C. \& O'Connell, P. R. Sulphate-reducing bacteria and hydrogen sulphide in the aetiology of ulcerative colitis. Br. J. Surg. 96(2), 151-158 (2009).

54. Rowan, F. et al. Desulfovibrio bacterial species are increased in ulcerative colitis. Dis. Colon Rectum 53(11), 1530-1536 (2010).

55. Gibson, G. R., Cummings, J. H. \& Macfarlane, G. T. Growth and activities of sulphate-reducing bacteria in gut contents of healthy subjects and patients with ulcerative colitis. FEMS Microbiol. Ecol. 9(2), 103-111 (1991).

56. Nava, G. M., Carbonero, F., Croix, J. A., Greenberg, E. \& Gaskins, H. R. Abundance and diversity of mucosa-associated hydrogenotrophic microbes in the healthy human colon. ISME J. 6(1), 57-70 (2012).

57. Devkota, S. et al. Dietary-fat-induced taurocholic acid promotes pathobiont expansion and colitis in Il10-/- mice. Nature 487(7405), 104-108 (2012).

58. Feng, Z. et al. A human stool-derived Bilophila wadsworthia strain caused systemic inflammation in specific-pathogen-free mice. Gut Pathog. 9, 59 (2017).

59. Tlaskalova-Hogenova, H. et al. The role of gut microbiota (commensal bacteria) and the mucosal barrier in the pathogenesis of inflammatory and autoimmune diseases and cancer: contribution of germ-free and gnotobiotic animal models of human diseases. Cell. Mol. Immunol. 8(2), 110-120 (2011).

60. Krych, L., Hansen, C. H., Hansen, A. K., van den Berg, F. W. \& Nielsen, D. S. Quantitatively different, yet qualitatively alike: a meta-analysis of the mouse core gut microbiome with a view towards the human gut microbiome. PLoS ONE 8(5), e62578 (2013). 
61. Smith, N. W., Shorten, P. R., Altermann, E., Roy, N. C. \& McNabb, W. C. Examination of hydrogen cross-feeders using a colonic microbiota model. BMC Bioinform. 22(1), 3-3 (2021).

62. Differding, M. K., Benjamin-Neelon, S. E., Hoyo, C., Østbye, T. \& Mueller, N. T. Timing of complementary feeding is associated with gut microbiota diversity and composition and short chain fatty acid concentrations over the first year of life. BMC Microbiol. 20(1), $56(2020)$.

63. Daly, K., Sharp, R. J. \& McCarthy, A. J. Development of oligonucleotide probes and PCR primers for detecting phylogenetic subgroups of sulfate-reducing bacteria. Microbiol. Read. Engl. 146(Pt 7), 1693-1705 (2000).

64. McOrist, A. L., Warhurst, M., McOrist, S. \& Bird, A. R. Colonic infection by Bilophila wadsworthia in pigs. J. Clin. Microbiol. 39(4), 1577-1579 (2001).

65. Larsen, N. et al. Gut microbiota in human adults with type 2 diabetes differs from non-diabetic adults. PLoS ONE 5(2), e9085 (2010).

\section{Author contributions}

H.E.- data acquisition, data analysis, drafting the work. G.L.- data acquisition, revising the work critically for content. D.C.W.- revising the work critically for content. J.C.C.-revising the work critically for content. P.R.O'C. - study design, revising the work critically for content.

\section{Funding}

This work was supported by Science Foundation Ireland Grant No. 09/IN.1/B2606.

\section{Competing interests}

The authors declare no competing interests.

\section{Additional information}

Correspondence and requests for materials should be addressed to H.E.

Reprints and permissions information is available at www.nature.com/reprints.

Publisher's note Springer Nature remains neutral with regard to jurisdictional claims in published maps and institutional affiliations.

(c) (1) Open Access This article is licensed under a Creative Commons Attribution 4.0 International License, which permits use, sharing, adaptation, distribution and reproduction in any medium or format, as long as you give appropriate credit to the original author(s) and the source, provide a link to the Creative Commons licence, and indicate if changes were made. The images or other third party material in this article are included in the article's Creative Commons licence, unless indicated otherwise in a credit line to the material. If material is not included in the article's Creative Commons licence and your intended use is not permitted by statutory regulation or exceeds the permitted use, you will need to obtain permission directly from the copyright holder. To view a copy of this licence, visit http://creativecommons.org/licenses/by/4.0/.

(C) The Author(s) 2021 